Case Report

\title{
The quintessence of breast leiomyosarcoma
}

\section{Ashwini Kannamma Kalimuthu, Raja Senthil Viswanathan*, Ponniah Iyyappan, Kaliyappa C.}

Department of General Surgery, Sri Ramchandra University, Chennai, Tamil Nadu, India

Received: 21 October 2018

Revised: 30 March 2018

Accepted: 02 April 2018

\section{*Correspondence:}

Dr. Raja Senthil Viswanathan,

E-mail: rajasenthilv@gmail.com

Copyright: ( ) the author(s), publisher and licensee Medip Academy. This is an open-access article distributed under the terms of the Creative Commons Attribution Non-Commercial License, which permits unrestricted non-commercial use, distribution, and reproduction in any medium, provided the original work is properly cited.

\begin{abstract}
Sarcoma of the breast is a rare condition. The biological differences from other primary breast tumours necessitate a corresponding difference in approach to diagnostic and management strategies. The rarity of the condition has made clinicopathological study difficult. Authors report a case of primary leiomyosarcoma in a 40-yr-old-women, with a $15 \times 9 \mathrm{~cm}$ bosselated swelling, involving all 4 quadrants of the left breast. Her clinical features, sonography and trucut biopsy were compatible with cystosarcoma phyllodes and she underwent a left mastectomy for the same. Later the histological and imunohistochemical studies established the diagnosis of leiomyosarcoma, grade 2.
\end{abstract}

Keywords: Mastectomy, Spindle cell carcinoma, Sarcoma breast

\section{INTRODUCTION}

Spindle cell lesions are a diverse spectrum of mesenchymal neoplasms consisting of spindle shaped cells that are differentiated based on cellularity, nuclear features, collagen content, and growth pattern.

Sarcomas of the breast account for less than $1 \%$ of all malignant tumors of the breast. Leiomyosarcomas belong to a less common subgroup (5\% to $10 \%$ ) of sarcomas of the breast. ${ }^{1}$ Although they represent only a small fraction of all breast pathology, this heterogeneous group of lesions has a large scope ranging from reactive and benign proliferations to aggressive malignant neoplasms. ${ }^{2}$

Spindle cell lesions have an increased number of spindled and pleomorphic cells with intermixed fascicles of relatively regular cells with fusiform nuclei. Given the similar appearance of these lesions, differentiating benign lesions from malignant growths can be challenging, posing a substantial diagnostic problem given the wide range of differential diagnoses and treatment approaches.
Spindle cell lesions are broadly categorized as cytomorphologically bland or pleomorphic.

- Mammary spindle cell lesions with a predominantly bland cytomorphology include pseudoangiomatous stromal hyperplasia (PASH), mammary fibromatosis, nodular fasciitis, myofibroblastoma, and scarring from biopsy or intervention.

- Mammary spindle cell lesions with pleomorphic cytomorphology include spindle cell carcinoma, angiosarcoma, malignant phyllodes tumor, solitary fibrous tumor /hemangiopericytoma, dermatofibrosarcoma protuberans, leiomyosarcoma, fibrosarcoma, malignant fibrous histiocytoma, and other metastatic spindle cell lesions to the breast. ${ }^{3}$

\section{CASE REPORT}

A 40-year-old postmenopausal woman with no prior medical problems presented with a rapidly enlarging, painless left breast mass for 8 months. There was nil significant family history. 
The patient had never had a prior mammogram or breast examination. On physical examination, a 10x9cm mass, well defined, lobulated, firm and mobile, with normal overlying skin and nipple-areola complex was found (Figure 1).

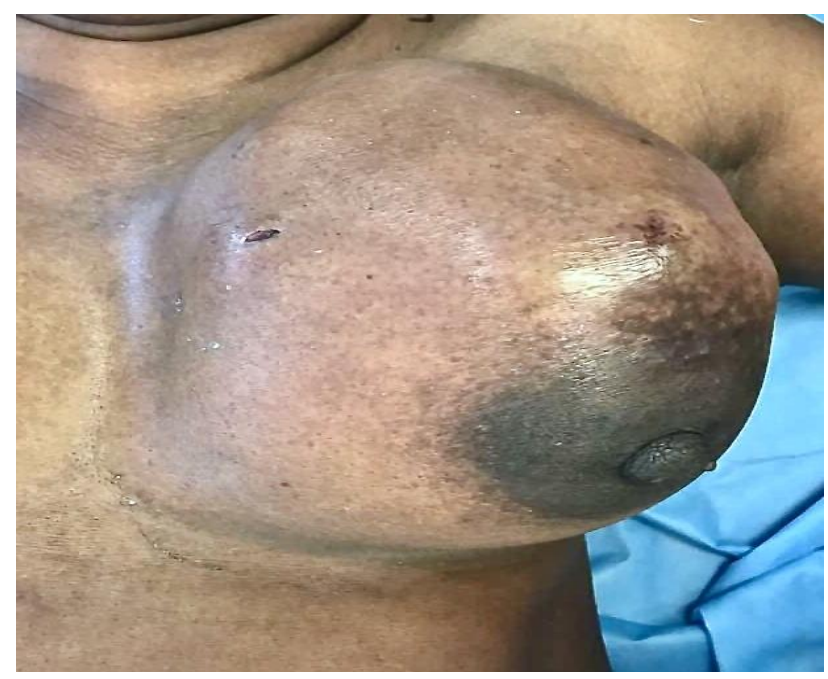

Figure 1: Bosselated lump.

She had no palpable axillary lymph nodes. Her ultrasound mammography and trucut depicted a well circumscribed, oval mass with a likely diagnosis of cystosarcoma phylloides (Figure 2).

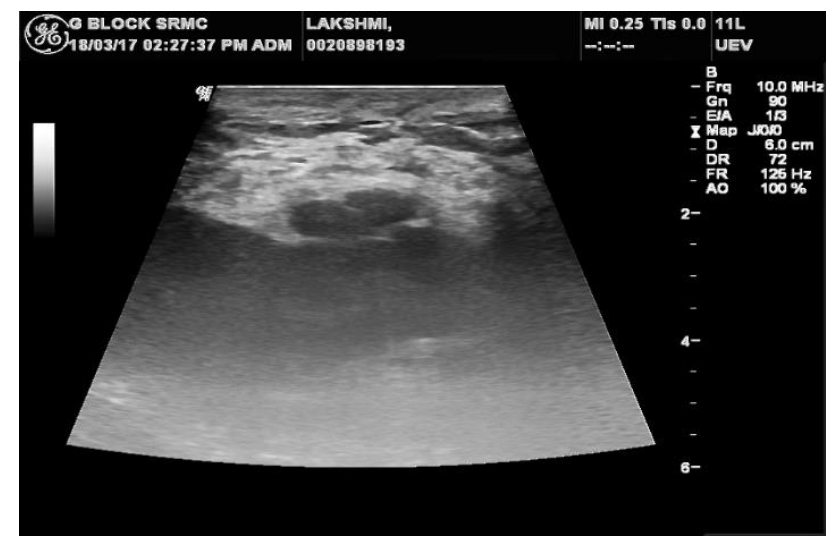

Figure 2: Ultrasound showing well defined lump.

Ultrasound scan of the chest and abdomen showed no lymphadenopathy, peritoneal, lung, or liver metastases. We proceeded on with left simple mastectomy and her post operative period was uneventful.

Later her pathological findings revealed;

- Grossly, a 16x13 cm single, large, globular, wellencapsulated mass, which was pearly white in color on both the outer surface as well as the cut surface with areas of whorling. No areas of hemorrhage, cystic degeneration, or necrosis were noted. Whereas focal areas of myxoid change were obvious.
- Microscopically, it was well-circumscribed, wellencapsulated, composed of spindle cells arranged as intersecting long fascicles in a collagenous background (Figure 3 ).

- Individual tumor cells were moderately pleomorphic, with round to oval nuclei, vesicular chromatin, and moderate amount of eosinophilic spindled cytoplasm with no epithelial component.

- The mass was confirmed to be leiomyosarcoma, Grade 2, which was completely excised with a rim of normal breast tissue containing terminal duct lobular units surrounded by mild fibrosis.

- Immunohistochemistry performed by the peroxidase technique revealed tumor cells to be strongly positive for smooth muscle actin (SMA) and vimentin, focally positive for betacatenin and negative for S100 and CD34 (Figure 4, Figure 5, Figure 6).

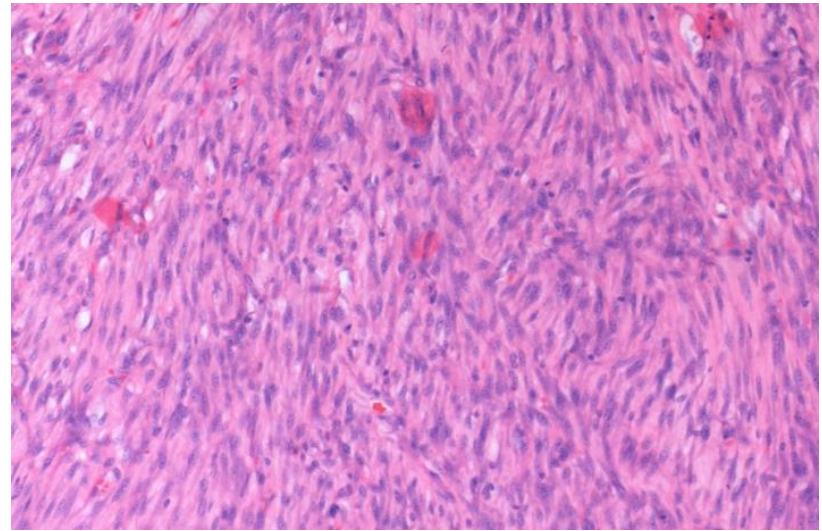

Figure 3: 100x spindle cells.

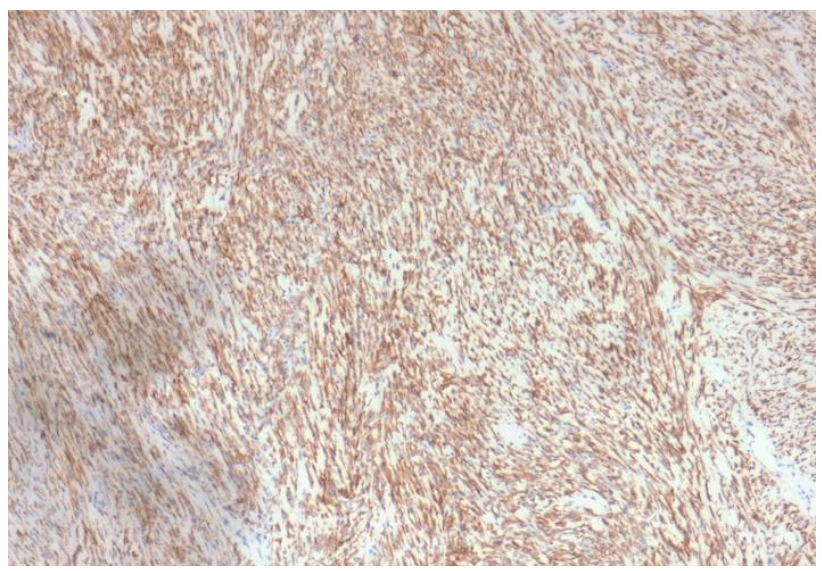

Figure 4: SMA (smooth muscle actin) positive.

\section{DISCUSSION}

Leiomyosarcoma of the breast is a malignancy originating from smooth muscle cells of the vascular walls within breast stroma or peri-areolar tissues. ${ }^{4-6}$ It presents in middle aged women as a slowly growing painless lump with rare skin involvement that is often localized in the peri-areolar tissues due to the location of the originating neoplastic cells. ${ }^{7}$ 


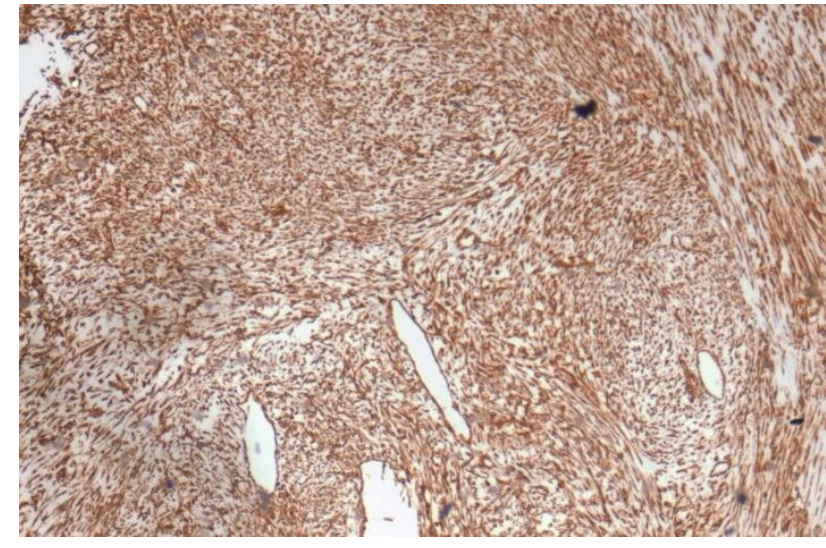

Figure 5: Vimentin positive.

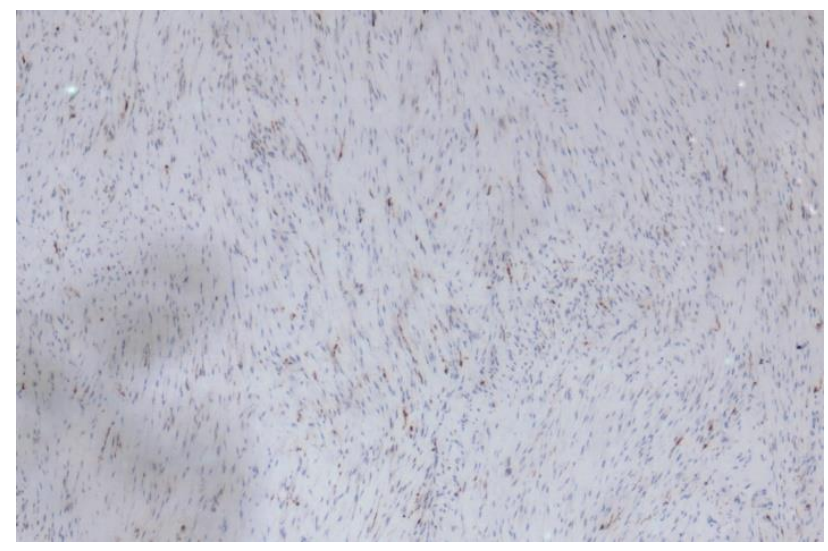

Figure 6: S100 positive.

The exact cell of origin is still debated, on either origin from smooth muscle of blood vessels, or nipple areola complex or myofibroblasts undergoing myoid transformation (candidate histogenetic mechanisms). ${ }^{8}$ As with other sarcomas, prior chemotherapy for either a primary breast carcinoma or any other malignancy is a risk factor reported in the literature. ${ }^{9}$

In the largest series on breast sarcomas; Mayo clinicover a span of 90 years (1910-2000), Adem et al reported twenty five cases of primary breast sarcomas have been reported, of which two were leiomyosarcoma. ${ }^{10}$ From the series on primary breast sarcomas from India, none of the 19 cases reported were a leiomyosarcoma. ${ }^{11}$

Mammography demonstrates a high-density, round or oval circumscribed mass with minimal local invasion. Typically, leiomyosarcoma lacks calcification. Ultrasound may show a circumscribed mass with either uniformly hypoechoic or heterogeneous internal echogenicity and possible cystic components. With these imaging features, leiomyosarcoma may be misdiagnosed as a fibroadenoma on pre-biopsy imaging. Although not well documented, MRI of leiomyosarcoma may demonstrate low signal on the T1-weighted sequences and isointense signal on the T2-weighted sequences.
The basis of treatment is surgery, either local excision or simple mastectomy. It appears that the type of surgical excision, whether excisional biopsy, simple mastectomy, or modified radical mastectomy, does not affect prognosis as long as the tumor is excised with an adequate margin.

In the present case, we performed a simple mastectomy and the width of the margin was obtained as at least 2.5 $\mathrm{cm}$. We hoped to recommend an adequate margin width around the excised tumor based on the previous case reports. However, we could not clarify the margin width in those studies due to lack of descriptions, as only a few papers stated concrete widths.

Metastatic disease is uncommon, but hematogeneous spread occurs more often than axillary lymph node metastases.

Axillary node metastasis was never before reported; thus, it is unlikely that axillary node dissection affords benefit and wasn't done on the case.

A few of the reports were about adjuvant therapy used in cases of leiomyosarcoma of the breast. Radiotherapy is a well-established treatment used to reduce local recurrence of leiomyosarcomas in other lesions of the body. Accordingly, post-operative radiotherapy may be indicated for cases with breast leiomyosarcoma, where a wide excision is not possible due to anatomical constraints. $^{12}$ As with other sarcomas, prior chemotherapy for either a primary breast carcinoma or any other malignancy is a risk factor reported in the literature. Most cases reported post mastectomy; however, treated by lumpectomy have been reported albeit with a marginally higher incidence of recurrence and metastases. ${ }^{13,14}$

\section{CONCLUSION}

Sarcomas remain a divergent group of diseases with variable presentation by site and histology. Following an excision with free margins, a histology examination with the appropriate immunohistochemistry is indispensable for an accurate diagnosis and in the prognosis of the disease. Molecular diagnosis is increasingly used, defining tumors when the presentation is atypical Molecular targets seem to be the most promising new approach to identify novel means to inhibit growth of these tumors and prevent death related to disease.

\section{ACKNOWLEDGEMENTS}

Authors would like to thank all the colleagues who provided expertise and moderated this paper, and in that line improved the manuscript significantly.

Funding: No funding sources

Conflict of interest: None declared

Ethical approval: Not required 


\section{REFERENCES}

1. EL M'rabet FZ, El Mesbahi O, El Hassouni K, khalil El Gueddari B. Primary breast leiomyosarcoma: case report and literature review. Health. 2011 Oct 17;3(10):620.

2. Cameron HM, Hamperl H, Warambo W. Leiomyosarcoma of the breast originating from myothelium (myoepithelium). J Pathol. 1974 Oct;114(2):89-92.

3. Raj SD, Sweetwood K, Kapoor MM, Raj KM, Nagi C, Sepulveda KA, Sedgwick EL. Spindle cell lesions of the breast: Multimodality imaging and clinical differentiation of pathologically similar neoplasms. European J Radiol. 2017 May;90:60-72.

4. Kim BR, Lee JH, Cho E, Kim DC, Park YM, Ha D$\mathrm{H}$, et al. Primary breast leiomyosarcoma located in the premammary zone: a case report. Clin Imaging. 2015;39:1105-7.

5. Munitiz V, Rios A, Canovas J, Ferri B, Sola J, Canovas P, et al. Primitive leiomyosarcoma of the breast: case report and review of the literature. Breast. 2004;13:72-6.

6. Shinto O, Yashiro M, Yamada N, Matsuoka T, Ohira M, Ishikawa $\mathrm{T}$, et al. Primary leiomyosarcoma of the breast: report of a case. Surg Today 2002;32:716-9.

7. Amaadour L, Benbrahim Z, Moumna K, Boudahna L, Amarti A, Arifi S, et al. Primary breast leiomyosarcoma. Case Rep Oncol Med. 2013;2013:732.

8. Pardo-MindÁn J, Garcia-Julian G, Altuna ME. Leiomyosarcoma of the breast: Report of a case. Am J Clin Pathol. 1974 Oct 1;62(4):477-80.
9. De la Pena J, Wapnir I. Leiomyosarcoma of the breast in a patient with a 10-year-history of cyclophosphamide exposure: a case report. Cases J. 2008 Dec;1(1):301.

10. Adem C, Reynolds C, Ingle JN, Nascimento AG. Primary breast sarcoma: clinicopathologic series from the Mayo Clinic and review of the literature. Br J Cancer. 2004 Jun 8;91(2):237-41.

11. Pandey M, Mathew A, Abraham EK, Rajan B. Primary sarcoma of the breast. J Surgical Oncol. 2004 Sep 1;87(3):121-5.

12. Fujita N, Kimura R, Yamamura J, Akazawa K, Kasugai T, Tsukamoto F. Leiomyosarcoma of the breast: a case report and review of the literature about therapeutic management. Breast. 2011 Oct 1;20(5):389-93.

13. Arista-Nasr J, Gonzalez-Gomez I, Angeles-Angeles A, Illanes-Baz E, Brandt-Brandt H, Larriva-Sahd J. Primary recurrent leiomyosarcoma of the breast: case report with ultrastructural and immunohistochemical study and review of the literature. Am J Clinical Pathol. 1989 Oct 1;92(4):500-5.

14. Chen KA, Kuo TT, Hoffmann KD. Leiomyosarcoma of the breast. A case of long survival and late hepatic metastasis. Cancer. 1981 Apr;47(7):1883-6.

Cite this article as: Kalimuthu AK, Viswanathan RS, Iyyappan P, Kaliyappa C. The quintessence of breast leiomyosarcoma. Int Surg J 2018;5:1923-6. 